\title{
A Study of the Influences of Application Interfaces on End User Training Outcomes
}

\author{
Raj Gururajan \\ Murdoch University, \\ Perth, Australia
}

r.gururajan@murdoch.edu.au

\author{
Dieter Fink \\ Edith Cowan University, \\ Perth, Australia
}

d.fink@ecu.edu.au

\begin{abstract}
Effective and efficient training is a key factor in determining the success of end user computing (EUC) activities in organisations. This study examines the influences of two application interfaces, namely icons and menus, on training outcomes. Training outcomes were measured in terms of effectiveness, efficiency and perceived ease of use. Effectiveness included the keystrokes used to accomplish tasks, the accuracy of correct keystrokes, backtracks and errors committed. Efficiency included the time taken to accomplish the given tasks. Perceived ease of use rates the ease of the training environment including training materials, operating system, application software and associated resources provided to users. To measure training outcomes, an experiment was conducted with 159 users. The study found that icon interfaces were more efficient and effective for end user training and menu interfaces were more easy to use in the given training environment. The findings appear to indicate that when the tasks become complicated, icons are limited in representing this complexity and menus appear to be providing better solutions for tasks accomplishments. There is a need for training designers to consider application interfaces when designing EUC training programmes.
\end{abstract}

Keywords: End User Computing, Training, Application Interfaces

\section{Introduction}

End User Computing (EUC) has gained in importance due to the rapid growth of Information Technology (IT) products and applications such as word processors, spreadsheets and databases. The availability of these products has enabled end users to satisfy their information processing needs in a number of ways. However, the EUC domain also exhibits a number of problems. They include experience gained in manual systems that are not suitable for computer systems (Moran, 1981), inability in recalling and using application command syntax (Sein et al., 1993), difficulty in applying software packages to specific tasks (Carrol \& Rosson, 1995), unstructured training materials and hence negative influences on the user (Gustafson \& Branch, 1997), and confusion about how to recover from errors (Olfman \& Madviwala, 1995).

Material published as part of these proceedings, either on-line or in print, is copyrighted by Informing Science. Permission to make digital or paper copy of part or all of these works for personal or classroom use is granted without fee provided that the copies are not made or distributed for profit or commercial advantage AND that copies 1) bear this notice in full and 2) give the full citation on the first page. It is permissible to abstract these works so long as credit is given. To copy in all other cases or to republish or to post on a server or to redistribute to lists requires specific permission from the publisher at publister@intormingscience.org
This has resulted in user training to be identified as a key factor responsible for ensuring the success of EUC (Sein et al.., 1999). Currently there is little known about how to design end user training programs that would yield efficiency and effectiveness. While it is possible to blame training programs that are inappropriate and ineffective, 
they cannot be singled out as the sole course of end users' difficulties in understanding the functional components of the application software. It can be argued that an equally important factor is the computer interface itself. Interfaces can be the difference between systems that are comprehensive and easy to use and systems that are frustrating, confusing and in the end may not be used at all. The objective of this study was to determine the most appropriate user interface for end users to learn an application software package.

\section{Research Variables and Hypotheses}

Interfaces can present a model of a computer system either directly or indirectly (Davis \& Bostrom, 1993). With direct representation, the form of objects such as icons to be manipulated is understood immediately. If the interface assumes an indirect form, then users activate the interface to perform a command. Usually the indirect form is provided by a menu interface. This study focuses on icons and menus because they represent direct and indirect forms of interfaces and are predominantly available in end user applications.

Training outcomes in this study were assessed using three measures - effectiveness, efficiency and ease of use. Effectiveness was measured in terms of scores obtained in completing a given task. Some studies in EUC have calculated scores based only on keystrokes (Davies et al., 1989; Davis \& Bostrom, 1993) and some others have accounted errors committed as well (Olfman \& Bostrom, 1991; Sein \& Bostrom, 1989). In this study we also included the number of times a user has reverted back to a previous step either because an error was committed or because the user was not sure whether a correct action was included. Thus effectiveness $=$ function (correct strokes, icon access, menu access, dialogue box interaction, errors, backtracks)

Training outcome efficiency was determined by the time taken in performing the given task. Prior studies (Olfman \& Madviwala, 1995; Sein et al., 1993) have used various methods such as asking users to estimate time spent in completing tasks, using manual clocks, using automated logs etc. Only few studies (Bohlen \& Ferrat, 1997; Carrol \& Mazur, 1986) have used the computer clock to automatically log the time spent on the experiment. This study incorporated a procedure to capture the time component using a computer clock to determine the time factor for efficiency. For efficiency, time is measured and was defined as efficiency = function (time, correct strokes).

The questionnaire to measure ease of use was adapted from Davies et al. (1989). The original questionnaire, which consisted of only 4 questions, was expanded to include 28 questions over five sections: (i) learning to use computers (5 questions), (ii) becoming skilful in using computers (5 questions), (iii) getting work out of computers (5 questions), (iv) operating computers (5 questions) and (v) using training materials (8 questions). Users responded to the statements on a Likert type scale ranging from 1 (disagree) to 5 (agree).

The application domain, Microsoft Project Management, was chosen for a number of reasons. The first reason being that we could ensure that subjects considered taking part in the study had no exposure to this application and thus project management concepts were new to them. Project management applications are not usually found in home applications and hence the exposure to this application from end user point of view is very low. The relative newness of the application, therefore, eliminated biases at the time of experiment. Furthermore, the interfaces available in project management applications are quite different from that of word processing and spreadsheet applications.

One would expect icons to facilitate more meaningful learning than menus because icons can portray the meaning of interfaces easily. The fact that icons provide anchoring concepts and give users the opportunity to work directly with those concepts suggests that icons have a unique capacity 
to reinforce and clarify the relationships between pre-existing knowledge in long-term memory and knowledge of a new application software package (Richardson, 1983). The expectation is that icons would be more effective in performing basic tasks. However, some studies suggest that menus are more effective in novel tasks because they help the user to navigate the system to its depth by using hierarchical features. This would help users to realise situations that are not directly represented by interfaces. In addition, menus can represent more functions of a system whereas icons cannot provide more functions because of their limitations in representing these functions via a symbol.

Furthermore, the operations of the two interface types are radically different from each other (Shih \& Alessi, 1994). Icons have a point-and-click type operation and menus have selections from a set of options with provision for navigation. The designs demonstrate different ways that users interact with systems (Robey \& Taggart, 1982). Although some comparisons had been made of icons and command-languages (Davis \& Bostrom, 1993), surprisingly little attention has focused on the use of menus or the impact of different interfaces on learning outcomes. We therefore stated our expected taring outcome in null form in hypothesis.

H1: There will be no difference in training effectiveness and efficiency outcomes between the subjects who preferred icons and those who preferred menus.

Davies et al. (1989) suggested that the acceptance of IT and its ultimate use is influenced in part by how easy it is to use. Given that factors such as interfaces can contribute to the ease of use, introducing systems with icons and menus may be one way to enhance this perception (Hutchins \& Norman, 1986). Icons provide a means to work with the applications directly and some users may perceive icons as superior in terms of ease of use. Conversely, users who are familiar with computer-based systems may perceive menus superior in terms of ease of use. The anticipated study outcome was stated in null form in hypothesis.

$\mathrm{H} 2$ : There will be no difference in training ease of use outcomes between the subjects who preferred icons and those who preferred menus.

\section{Research Method}

Our literature review indicated that EUC studies have predominantly used an experimental approach with hands-on tasks (e.g. Bohlen, 1997; Davies, 1989; Davis, 1993; Sein, 1993; Olfman, 1994). We adopted the same approach; the study was conducted in a laboratory-like setting where subjects used computers to perform hands-on tasks. We preceded the experiment with a training session. During training, subjects were requested to work on the training materials and allowed to ask questions to which they were provided answers. Once the training was completed, subjects were asked to nominate their choice of interface - icon or menu. Subjects were asked to return the training materials to the instructor.

Once the training component was completed, subjects participated in the hands-on task testing. In addition, they were given an introduction to the overall operations, how to save the data and where to save the data. This study used a time frame of 45 minutes for the hands-on experiment component because previous studies in EUC training have employed a duration of about 45 minutes for the purpose of training (Blili et al., 1998; Bohlen \& Ferrat, 1997; Davis \& Bostrom, 1993; Sein \& Bostrom, 1989). Once the tasks were completed, subjects were asked to store their file at a specified disk volume. A total of 159 subjects completed the hands-on tasks exercises of which 81 used the icon and 78 used the menu approach.

Task performance was captured by ScreenCAM software that ran in conjunction with Microsoft Project. Reliability estimates were performed on the factors used to measure training outcomes. 
The reliability analysis was performed on correct strokes, icon access, menu access, dialogue box interaction, and backtracking, because these factors are used to determine effectiveness. It was found that these items correlated significantly $(\mathrm{p}<0.01)$ with each other, and the alpha value was 0.72. According to Simon et al. (1996) such an alpha value is within an acceptable range.

Subjects also completed the ease of use questionnaire. The internal consistency reliability for the 28 -items was calculated in two different ways. First, correlation between each item under the five categories - learning to use computers, becoming skilful at using computers, getting work out of computers, operating the computers and using the training materials - were calculated to ascertain homogeneity. The questionnaire was found to be correlating with values over 0.70 for all items indicating that questionnaire items were strongly correlated. The second test - Cronbach alpha was performed to ascertain inter-item reliability. This produced a value of 0.91 indicating the reliability of items in the five categories.

\section{Data Analysis}

A frequency distribution was compiled on the three training outcome measures - efficiency, effectiveness and ease of use. Six responses were found to be beyond the normal distribution range of the samples. Many studies choose to ignore such responses, usually called 'outliers', during the analysis of data because they may distort the analysis (Zikmund, 1994). Similarly, these responses were eliminated from the data set in this study. Furthermore, the data were checked for normality and found to be normal. In addition to this, the data was tested for Skewness and Kurtosis in order to find any aberrations. The Skewness and Kurtosis lay between acceptable limits $(-1.00$ to +1.00$)$ indicating the normality of the data.

Table 1 summarises the descriptive analysis that was performed on the responses obtained.

\begin{tabular}{|c|l|r|r|r|r|}
\hline Interface & & Minimum & Maximum & \multicolumn{1}{c|}{ Mean } & Std. Deviation \\
\hline Icon & efficiency & 11.78 & 76.80 & 37.10 & 13.72 \\
\hline & effectiveness & 15.00 & 93.00 & 53.86 & 17.88 \\
\hline & ease of use & 1.31 & 5.00 & 3.39 & 0.66 \\
\hline Menu & efficiency & 17.16 & 76.32 & 40.38 & 13.90 \\
\hline & effectiveness & 11.00 & 64.00 & 37.70 & 10.99 \\
\hline & ease of use & 1.74 & 4.96 & 3.71 & 0.73 \\
\hline
\end{tabular}

Table 1: Descriptive Analysis of Data

Effectiveness was defined as a function of correct strokes, icon access, menu access, dialogue box interaction, errors and backtracks. As seen in Table 1, icon interfaces were found to be more effective with a mean value of 53.86 to complete the given set of tasks than menu interfaces with a mean value of 37.70. Efficiency was measured in "time"; less time taken to complete tasks indicates efficiency. Subjects who preferred icon interfaces scored a mean time of 37.10 minutes to accomplish the set of 12 given tasks compared to 40.38 minutes scored by subjects who preferred menu interfaces. For ease of use Table 1 indicates that users who preferred menu interfaces rated 
menus to be easy to use in the given training environment with a mean value of 3.71 on the 5 point scale compared with the users who preferred icon interfaces with mean value of 3.39.

To test our hypotheses, we conducted an ANOVA. This indicated that the computer interface effect was significant in determining efficiency and effectiveness $(\mathrm{p}=0.063, \mathrm{~F}=3.511$ for efficiency and $\mathrm{p}=0.000$ and $\mathrm{F}=40.778$ for effectiveness). Therefore, the hypothesis that there will be no difference in efficiency and effectiveness training outcomes between icon-based subjects and menu-based subjects was rejected. The second hypothesis that there will be no difference in the ease of use outcome between icon-based subjects and menu-based subjects did not show any significance $(\mathrm{p}=0.221, \mathrm{~F}=1.514)$ and hence was not rejected.

\section{Discussion}

\section{Efficiency and Effectiveness}

The results of statistical tests provided strong evidence to support the hypotheses that interfaces play a crucial role in determining the training outcomes of efficiency and effectiveness. Users who preferred icons were shown to improve in efficiency and effectiveness compared with the users who preferred menu interfaces. These findings are in agreement with other studies such as Chin (1984); Fryer (1991); Shneiderman (1982) and Walkenbach (1992) which have established that direct manipulation interfaces such as icons enhances user performance. However, it should be noted that these studies have established the superiority of icon interfaces in an operating system environment and not in an application environment. This difference is worth noting because in an operating system environment tasks are handled on a component basis such as moving a file to a recycle bin. In an application environment, as used in this study, operations need to be in a sequential order to accomplish a given task and hence continuity between operations is essential. Nonetheless, this study found that using icon interfaces enhanced performance more than using menu interfaces in the project management domain.

The superiority of icon interfaces in this study can be explained using Assimilation Theory. The proposition of Assimilation Theory (Ausubel \& Robinson, 1968) is that, in order to achieve meaningful learning, an individual must integrate new knowledge with existing knowledge available in long-term memory. In order to achieve this integration the individual must first possess an appro-

priate assimilative context. This context, in turn, provides a basis for thinking about and reasoning with the new knowledge. In this study, the icon interfaces provided the appropriate assimilative context by presenting subjects with an on-screen conceptual model of the system. For example, certain tasks of the project management application such as 'linking sub-tasks' are provided by the icon interfaces readily available on screen. Subjects who preferred icon interfaces easily understood the meaning of these interfaces and this understanding led to greater efficiency and effectiveness. Menus did not provide this same understanding, as users needed to interpret the menu commands to arrive at some form of understanding.

Bostrom (1990) stated that application interfaces play a crucial role in developing mental models by providing an internal representation of the system and, in this study, icons portrayed functions of Microsoft Project better than menus. In other words, icon interfaces provided conceptual models of the functions of Microsoft Project by providing the meaning of the interface language on screen. Further, users following the 'mapping via training' path used these icon interfaces to easily form a conceptual model of various functions of the application. The advantages of using conceptual models for learning computer skills have been confirmed in a number of studies (Borgman, 1986; Davis \& Bostrom, 1993; Mayer, 1981; Sein \& Bostrom, 1989). 
A significant additional advantage of icon interfaces over menu interfaces is that they allow users to work directly with on-screen representations and to draw strong analogies with concrete objects such as recycle bins and diskettes. For instance, to save a file, icon interfaces in a Windows environment provide an icon representing a floppy diskette. Users immediately understand the meaning of such icons which enables them to readily understand and undertake a task. Hutchins et al. (1986) suggested that this can lead to a substantial reduction in a user's cognitive processing load and Shneiderman (1982) stated that this can reduce the cognitive load placed on information processing. This reduction could have yielded better results for users who preferred icon interfaces.

The findings of this study differ from those of Carrol \& Rosson (1995) who found menus to generate better outcomes than icons. One possible explanation is the platform on which Carrol \& Rosson's training was provided. While this study used a Windows platform, they used a DOS platform to enter command strings. In a DOS platform, most of the operating system commands such as 'save' need to be entered in text string form, whereas, in this study these commands are chosen from a limited set of command options in a Windows environment.

\section{Ease of Use}

Despite this study supporting the superiority of icon interfaces in effectiveness and efficiency, there is no evidence to support the superiority of icon interfaces in terms of ease of use. In fact, subjects who preferred menu interfaces were deemed to be better compared to subjects who preferred icon interfaces according to the mean responses. This can be explained by the difficulties encountered in applying icon interfaces to certain complex situations where users had to perform a combination of steps rather than a single icon click. For instance, when time scales needed adjustment, icon subjects had the option to move the timescale by the 'drag and drop' method. On the other hand, to arrive at a precise time scale, icon users needed to make necessary modifications to the time scale presented on screen by Microsoft Project. It was noted while replaying ScreenCAM files that, users who preferred icons were not fully conversant with the various details of time-scale adjustments, such as changing the project schedule from month to week, and found icon interfaces difficult to use with respect to this method. Subjects who preferred menu interfaces, due to information cues provided by the application, would have found the application easier to use under these circumstances.

Novel situations require manipulation plans and these in turn require searching both short-term memory and long-term memory for information to match with the information available on hand (Ausubel \& Robinson, 1968). Information searching in novel situations needs to be disciplined and logical. Menu interfaces provide assistance in searching for commands based on hierarchical grouping, which icon interfaces do not. Therefore, users who prefer menu interfaces might have judged the approach easier to use. The project management software application was a novel situation for the users in this study and menus may have provided a better way of exploring the command strings required to perform a task. Further, the command strings found in menu options may have enabled users to understand the context in order to explore further. It was noted while replaying the ScreenCAM files that, whenever subjects who preferred icon interfaces found the interface to fail to provide apparent and trivial solutions, attempted to use menus despite their preference for icons.

Our study findings differed from those of Dumais \& Jones (1985) who established the superiority of 'ease of use' of icon interfaces. In their study subjects simply retrieved uniformly shaped objects similar to icons; the retrieval involved just recalling shapes and did not involve complicated operations. By contrast, subjects in this study manipulated a range of different icons on a com- 
puter screen. For example, in Microsoft Project, icons range from a commonly available shape such as a floppy diskette icon to an uncommon shape such as a link icon.

Similarly, the difference between the findings of this study and the study by Davis \& Bostrom (1993) that has established the superiority of icons in terms of ease of use may be due to the fact that in the their study, subjects performed short, discrete sequences of operations using icons. These short operations involved simply recalling pieces of information and, again, did not lead to a cohesive set of operations. By contrast, subjects in this study performed relatively complicated operations that required them to formulate and execute manipulation plans. Menus appear to facilitate these complicated operations in a better way than icons in the application environment of this study. These would have enabled the subjects in this study to rate menu interfaces easier to use.

\section{Conclusion}

Based on the above findings, it can be asserted that users who preferred icons scored better effectiveness and efficiency results than users who preferred menus because of the assimilation of context through the representation of the icons. However, this study also indicated that when the tasks become complicated, icons are limited in representing this complexity and menus appear to be providing better solutions for tasks accomplishments. This is reflected in the 'ease of use' survey where users rated menus to be better compared with icons.

\section{References}

Ausubel, D. P., \& Robinson, F. G. (1968). School Learning: an introduction to education psychology. New York, Holt: Rinehart and Winston.

Blili, S., Raymond, L., \& Rivard, S. (1998). Impact of task uncertainty, end user involvement, and competence on the success of end user computing. Information \& Management, 33(3), 137-153.

Bohlen, G., \& Ferrat, T. (1997). End user training: An experimental comparison of lecture versus computer-based training. Journal of End User Computing, 9(3), 4-27.

Borgman, C. L. (1986). The user's mental model of an information retrieval system. International Journal of Man Machine Studies, 24(1), 47-64.

Bostrom, R. P., Olfman, L., \& Sein, M. K. (1990). The importance of learning style in End User Training. MIS Quarterly, 14(1), 101-119.

Carrol, J. M., \& Mazur, S. A. (1986). LisaLearning. IEEE Computer, 19(11), 35 - 49.

Carrol, J. M., \& Rosson, M. (1995). Managing evaluation goals for training. Communications of the ACM, 38(7), 4048.

Chin, C. (1984). LisaSoftware. Info World( November), 27.

Davies, F. D., Bagozzi, R. P., \& Warshaw, P. R. (1989). User acceptance of computer technology: A comparison of two theoretical models. Communications of the ACM, 35(8), 982-1003.

Davis, S., \& Bostrom, R. (1993). Training end users: An experimental investigation of the roles of the computer interface and training methods. M I S Quarterly, (March), 61-79.

Dumais, S. T., \& Jones, W. P. (1985). A Comparison of symbolic and spatial filing. Conference Proceedings: Human Factors in Computer Systems: Association for Computing Machinery, 127-130.

Fryer, B. (1991). Windows gives WordPerfect a shiny look. PC World, (November), 83-87.

Gustafson, K., \& Branch, R. (1997). Revisioning models of instructional development. Educational Technology Research \& Development, 45(3), 73-88.

Hutchins, E. L., Hollan, J.D, \& Norman, D. A. (1986). The direct manipulation interfaces in user centered systems design - New perspectives in human-computer interaction. In D.A. Norman and S.W.Drapereds (Eds.), 87-124. 
Study of the Influences of Application Interfaces

Mayer, R. E. (1981). The psychology of how novices learn computer programming. Computing Surveys, 13(1), 121141.

Moran, T. P. (1981). An Applied Psychology of the User. Computing Surveys, 13, 1 - 11.

Olfman, L., \& Bostrom, R. P. (1991). End user software training: An experimental comparison of methods to enhance motivation. Journal of Information Systems, 1(4), 249-266.

Olfman, L., \& Madviwala, M. (1995). An experimental analysis of end-user software training manuals. Information systems journal, 5(1), 19-36.

Richardson, A. (1983). Imagery: Definition and Types. New York: Wiley.

Robey, D., \& Taggart, W. (1982). Human information processing in information and decision support systems. MIS Quarterly, 6(1), 61-73.

Sein, M. K., \& Bostrom, R. P. (1989). Individual differences and conceptual models in training novice users. Human Computer Interaction, 4(3), 197-229.

Sein, M. K., Bostrom, R. P., \& Olfman, L. (1999). Rethinking end user training strategy: applying a hierarchical knowledge level model. Journal of End User Computing, 11(1), 32-39.

Sein, M. K., Bostrom, R. P., Olfman, L., \& Davis, S. (1993). Visualisation ability as a predictor of user learning success. International Journal of Man-Machine Studies, 39, 599-620.

Shih, Y., \& Alessi, S. (1994). Mental Models and Transfer of Learning in Computer Programming. Journal of Research on Computing in Education, 26(2), 154 - 175.

Shneiderman, B. (1982). The future of interactive systems and emergence of direct manipulation. Behaviour and Information Technology, 1(3), 237-256.

Simon, S., Grover, V., J, T., \& Whitcomb, K. (1996). The relationship of information system training methods and cognitive ability to end user satisfaction, comprehension and skill transfer: A longitudinal field study. Information Systems Research, 7(4), 466-490.

Walkenbach, J. (1992). Spreadsheets: The next generation. PC World, 232-240.

Zikmund, W. (1994). Business research methods ( International Ed.). Orlando, FL: The Dryden Press.

\section{Biographies}

Raj Gururajan is Senior Lecturer at Murdoch University in Perth Western Australia. Besides his interests in end user computing, he caries out research in e-commerce with a particular focus on wireless computing.

Dieter Fink is Associate Professor at Edith Cowan University in Perth, Western Australia. His research interests focus on IT evaluation and benefits management relevant to e-commerce and the use of IT by SMEs which includes end user computing. 